\title{
Difficult Biliary Cannulation in Endoscopic Retrograde Cholangiopancreatography: An Overview of Advanced Techniques
}

Authors:

Disclosure:

Author contributions:

Acknowledgements:

Received:

Accepted:

Keywords:

Citation:
Brian M. Fung, ${ }^{1,2}$ Teodor C. Pitea, ${ }^{2}$ *James H. Tabibian 3,4

1. Division of Gastroenterology and Hepatology, Department of Internal Medicine, University of Arizona College of Medicine - Phoenix, Arizona, USA

2. Banner - University Medical Center Phoenix, Arizona, USA

3. Division of Gastroenterology, Department of Medicine, Olive View-UCLA Medical Center, Sylmar, California, USA

4. David Geffen School of Medicine at UCLA, Los Angeles, California, USA

*Correspondence to jtabibian@dhs.lacounty.gov

The authors have declared no conflicts of interest.

Fung reviewed the literature for relevant original studies and other content, designed the figures, and drafted the manuscript. Pitea and Tabibian critically reviewed the manuscript. All authors provided critical input and approved the final version of the manuscript.

This work was supported in part through the United States National Institutes of Health (NIH) grant UL1 TRO00135.

09.01 .21

26.03.21

Endoscopic retrograde cholangiopancreatography (ERCP), fistulotomy, papillotomy, post-ERCP pancreatitis (PEP), precut, selective biliary cannulation, sphincterotomy.

EMJ Hepatol. 2021;9[1]:73-82.

\section{Abstract}

Endoscopic retrograde cholangiopancreatography (ERCP) plays a significant role in the treatment of a vast array of pancreatobiliary diseases. However, despite significant progress in the optimisation of ERCP methods and accessories, the technical and clinical success of ERCP can vary significantly due to a variety of patient and operator factors. Over the past several decades, a number of advanced techniques have been developed to improve cannulation success rates, including the use of doubleguidewire, pancreatic duct accessory-assisted, precut, and rendezvous techniques. Here, the authors provide an update and overview of the existing advanced techniques used in cases of difficult biliary cannulation, as well as the approach to their selection.

\section{INTRODUCTION}

Over the years, endoscopic retrograde cholangiopancreatography (ERCP) has been transformed from primarily a diagnostic modality into a largely therapeutic technique that is now the preferred minimally invasive treatment for

many pancreaticobiliary diseases. However, despite significant progress in the optimisation of ERCP methods and accessories, selective biliary cannulation can be one of the most challenging and rate-limiting aspects of ERCP. Even in the hands of experienced endoscopists, failure of biliary cannulation can occur in $5-15 \%$ of 
cases. ${ }^{1}$ Furthermore, there is a non-insignificant risk of post-ERCP pancreatitis (PEP) and other adverse events. ${ }^{1-3}$ When confronted with a case of difficult biliary cannulation, an endoscopist must decide whether to continue with standard cannulation techniques, switch to more advanced techniques, consult a more senior colleague, or abort the procedure and consider re-attempting at a later time.

This review provides an overview of the most common advanced techniques currently used when standard selective biliary cannulation techniques are unsuccessful. In particular, the authors discuss the double-guidewire cannulation technique, pancreatic stent-assisted cannulation technique, precut papillotomy, precut fistulotomy, transpancreatic septotomy, rendezvous, and other advanced techniques, as well as the approach to their selection.

\section{PANCREATIC DUCT WIRE- AND STENT-ASSISTED TECHNIQUES}

\section{Pancreatic Guidewire and Double-Guidewire Technique}

Cannulation of the pancreatic duct is typically easier than cannulation of the bile duct given the angle at which the pancreatic duct inserts into the hepatopancreatic ampulla. Thus, if a guidewire is inadvertently placed in the pancreatic duct, one strategy is to keep the guidewire in the main pancreatic duct and subsequently attempt to cannulate the bile duct using a cannula/sphincterotome and contrast (i.e., single-guidewire technique), while another is to use a second guidewire (doubleguidewire technique [DGT]) (Figure 1). ${ }^{4}$ Either way, the guidewire in the pancreatic duct can help to straighten the hepatopancreatic ampulla, separate the biliary and pancreatic orifices, and help to identify the respective biliary and pancreatic axes. ${ }^{5}$ The guidewire also partially occludes the pancreatic orifice, thus helping to deflect the sphincterotome (or second guidewire) away from the pancreatic duct and towards the common bile duct (CBD), facilitating selective biliary cannulation. ${ }^{6}$

Early studies suggested that DGT could improve biliary cannulation rates. ${ }^{7}$ However, subsequent studies have found DGT to be no better than standard biliary cannulation, and the technique even appears to increase the risk of PEP. A recent meta-analysis of seven randomised controlled trials found that DGT significantly increased the risk of PEP compared to other endoscopic techniques (risk ratio [RR]: 1.98; 95\% confidence interval $[\mathrm{Cl}]$ : 1.14-3.42). ${ }^{8}$ If employed, the authors recommend placing a temporary plastic pancreatic duct stent to help mitigate this risk, as discussed below.

\section{Pancreatic Stent-Assisted Technique}

A variation on DGT is the use of a pancreatic stent. ${ }^{9}$ In this technique, a short ( $3-5 \mathrm{~cm}$ long), smallcaliber (3-5 Fr) pancreatic stent is immediately placed after cannulating the pancreatic duct. This temporary stent helps to identify the pancreatic axis and occludes the pancreatic duct, thus deflecting the guidewire into the CBD. The stent typically falls out by itself within a week or two after the procedure (depending on the size and type of stent and the depth of insertion); however, a stent removal procedure may be needed if the stent does not pass on its own. ${ }^{10}$

This technique has been demonstrated to have a high rate of successful biliary cannulation, and the placement of a prophylactic pancreatic stent has been shown to lower the rate of PEP." In a study of 70 patients who underwent pancreatic guidewire-assisted biliary cannulation, patients who underwent stent placement had a significantly lower frequency of PEP compared to those without stent placement (2.9\% versus 23.0\%, respectively; $p=0.0096) .{ }^{12}$ Similarly, a recent multicentre randomised controlled trial found that prophylactic pancreatic stenting after inadvertent cannulation of the pancreatic duct significantly reduced the rate of PEP (odds ratio [OR]: 0.43). ${ }^{13}$ Over the past decade, multiple meta-analyses have supported these findings (OR: 0.22-0.39). ${ }^{14-20}$ This technique also appears to be cost-effective for high-risk patients, likely due to the lower rates of PEP associated with this technique. 21,22 The European Society of Gastrointestinal Endoscopy (ESGE) currently recommends prophylactic pancreatic stenting in patients with inadvertent guidewire insertion/opacification of the pancreatic duct or after double-guidewire cannulation. ${ }^{23}$ 

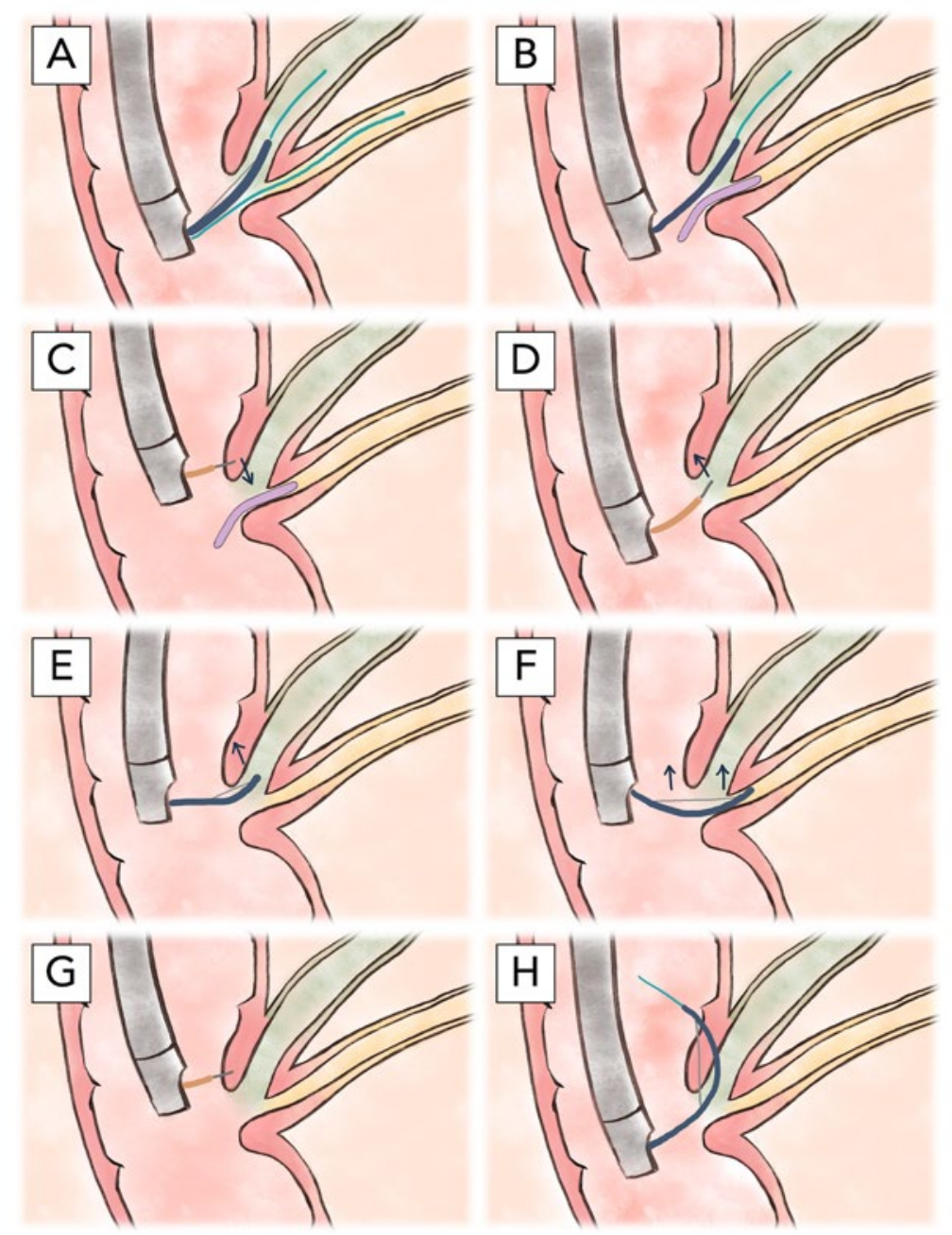

\section{Figure 1: Illustration of various advanced common bile duct cannulation techniques.}

A) Double-guidewire technique. A guidewire (light blue) is first placed (often inadvertently) in the main pancreatic duct (yellow). This facilitates adjacent advancement of a second guidewire through a sphincterotome (blue) into the hepatopancreatic ampulla (via either a no-touch or touch technique) and thereafter into the common bile duct (green). B) Pancreatic stent-assisted technique. A pancreatic duct stent (purple) is first placed over a guidewire in the main pancreatic duct. Similar to the double-guidewire technique, this technique facilitates adjacent placement of a guidewire through a sphincterotome into the hepatopancreatic ampulla and onward into the common bile duct. C) Precut sphincterotomy over a pancreatic duct stent. A needle-knife catheter (orange) is used to cut inferiorly, starting suprapapillary in the (expected) location of the intraduodenal segment of the hepatopancreatic ampulla, towards the pancreatic duct stent. D) Precut papillotomy. A needle-knife is used to cut superiorly in a biliary (11-12 o'clock) orientation (i.e., vector), starting from the papillary orifice. E) Pull-type precut. A (semi-)seated sphincterotome is used to cut superiorly in a biliary orientation, starting from the papillary orifice. F) Transpancreatic precut sphincterotomy. A sphincterotome is inserted into the hepatopancreatic ampulla/distal pancreatic duct and, when repositioning into the distal bile duct is not feasible, used to cut superiorly, cutting through the septum in a biliary orientation. G) Precut supra-papillary fistulotomy. A needle-knife is used to incise directly into the intraduodenal segment of the distal bile duct/proximal hepatopancreatic ampulla, superior to the level of the papillary orifice. $\mathbf{H}$ ) Intramural incision. After inadvertent creation of a false tract with a guidewire through the intraduodenal segment of the common bile duct, a sphincterotome is used to unroof the papilla to facilitate direct cannulation. Note: all illustrations show a major papilla with a conventional hepatopancreatic ampulla (i.e., a shared ductal orifice and normal common channel length); however, technique may vary in the case of variant (peri-) ampullary anatomy. 
However, of note, placement of a pancreatic stent can compress the biliary orifice and make standard approaches more difficult; thus, the risks and benefits of immediate pancreatic stent placement should be carefully considered. ${ }^{5}$

\section{Precut Sphincterotomy Over Pancreatic Stent}

The precut over pancreatic stent (PPS) technique is generally thought of as an extension of the pancreatic stent-assisted technique. ${ }^{24}$ As previously mentioned, the placement of a pancreatic stent can often narrow the papillary orifice, thus making cannulation of the bile duct more difficult. To improve access, an incision using a needle-knife can be made, starting from above the papillary orifice and extending downward towards the pancreatic stent. A retrospective study found that PPS was associated with significantly higher biliary cannulation rates (96.9\% versus $86.1 \%$; $\mathrm{p}=0.0189)$ and fewer adverse events (7.1\% versus $33.0 \%$; $p<0.001) .{ }^{25}$

\section{PRECUT TECHNIQUES}

When biliary cannulation fails with the previously discussed techniques, a variety of precut techniques can be employed to create access to the CBD. These techniques involve the use of a cutting tool, often a needleknife (a fine, straight, wire-type needle), to make an incision in the ampulla to allow access to the bile duct for successful selective biliary cannulation. Unlike traditional biliary sphincterotomy that enlarges the biliary opening for therapeutic interventions (e.g., extraction of stones or placement of stents), the precut is used solely for biliary access.

\section{Precut Papillotomy}

A common precut technique is precut papillotomy. ${ }^{26}$ In this technique, a needle-knife is used to carefully dissect the major duodenal papilla to directly visualise and cannulate the CBD. The papillotomy is first initiated by placing the needle-knife at the top of the papillary orifice, near the 12 o'clock position, in the presumed axis of the bile duct. An incision is then made in the cephalad direction by extending the needle-knife upward towards the roof of the papilla, with the electrical current on. While the length and depth of the incision depends on the size and characteristics of the papilla, incisions should generally be made in short increments to avoid cutting too deep and causing bleeding, perforation, or acute pancreatitis. ${ }^{27}$ Once the muscle layer of the biliary sphincter muscle is visualised (which can often be recognised by its whitish, concentric circular appearance), the papilla can be cannulated, or an additional cut can be made to transect the biliary sphincter, allowing direct cannulation of the CBD.

\section{Pull-Type Precut Papillotomy}

Pull- or traction-type precut papillotomy is a variation of the precut papillotomy technique, originally used after successful cannulation of the bile duct. ${ }^{28}$ However, the same device is now used as a method of obtaining access to the bile duct. In this technique, a short-nosed sphincterotome is used instead of a needle-knife. Shallow cannulation of the common channel is first performed using the tip of the sphincterotome. A small 1-2 $\mathrm{mm}$ cut is then made, changing the shape of the biliary orifice from a circle to a teardrop and improving access to the CBD. There are four major advantages of this sphincterotome: a lower risk of injury to the pancreatic duct due to protection by the insulated convex catheter tip; a more controlled incision with the tip of the instrument providing stability; the ability to control the direction of the incision by orientation of the cutting wire; and the ability to perform sphincterotomy without another device. ${ }^{29}$ This technique has been demonstrated to have a high rate of biliary cannulation, with no increased rate of complications when compared to standard cannulation techniques. ${ }^{29-31}$

\section{Transpancreatic Precut Sphincterotomy}

In patients with small or difficult to locate papilla, precut papillotomy or precut fistulotomy using a needle-knife may be difficult. ${ }^{32}$ In these cases, the transpancreatic precut sphincterotomy (TPS) technique may be used to achieve biliary access. In this technique, a standard sphincterotome is superficially inserted into the ampulla or main pancreatic duct oriented towards the 11 o'clock position. An incision is then made by pushing the sphincterotome 
upward towards the CBD. Both the septum and ampullary sphincter are cut. This technique is thought to allow better control of the depth of incision compared to a standard needleknife and eliminates the need to exchange the sphincterotome for a needle-knife..$^{33}$ The use of a guidewire to assist cannulation of the pancreatic duct prior to TPS has also been described. ${ }^{34,35}$ Whether a guidewire is used or not, the TPS technique appears to have a higher rate of biliary cannulation than needleknife precut papillotomy. ${ }^{35,36}$ The associated risk of PEP can also be lowered when a pancreatic stent is placed. ${ }^{37}$

\section{Precut Fistulotomy}

Unlike in precut papillotomy where an incision is made extending from the papillary orifice in an upward direction, precut fistulotomy involves the making of an incision using a needle-knife in an area of the papilla above the papillary orifice so that a fistula is made between the duodenal lumen and the CBD lumen. ${ }^{38-40}$ This incision can be extended superiorly or inferiorly toward the papillary orifice using the needle-knife, but does not reach the papillary orifice, allowing the sphincter and papillary orifice to remain intact. This method has been reported to have a high cannulation rate and a lower risk of PEP than precut papillotomy, which may be attributed to low likelihood of thermal injury to the papillary orifice and pancreatic duct. ${ }^{41}$

\section{Intramural Incision (for Unroofing False Tracts)}

The intramural incision technique (also known as Burdick's technique) can be used when a guidewire inadvertently creates a false tract in the 10-11 o'clock direction through the intraduodenal segment of the bile duct during attempted biliary cannulation. ${ }^{42}$ In this scenario, an intramural incision can be made using a sphincterotome or needle-knife, thus unroofing the papilla and exposing the CBD for cannulation. Several small studies have suggested a high rate of success and minimal complications with this technique. ${ }^{43,44}$ The intramural incision technique illustrates how an undesired event can be used to the endoscopist's advantage.

\section{COMPARISON AND TIMING OF PRECUT TECHNIQUES}

Since the advent of endoscopic biliary sphincterotomy, numerous studies have evaluated the effectiveness and risks of precut techniques. While there is still no consensus on which technique is best, one recent systematic review and meta-analysis of 14 studies found that TPS was associated with a higher success rate than DGW (OR: 2.72; 95\% Cl: 1.30-5.69) and precut papillotomy (OR: 2.32; $95 \% \mathrm{Cl}$ : 1.37-3.93), but not different from that of precut fistulotomy (OR: 1.38; 95\% Cl: 0.32-5.96). ${ }^{45} \mathrm{In}$ the same meta-analysis, the rate of PEP was not significantly different between TPS and DGW (OR: 0.72; 95\% Cl: 0.24-2.10) and between TPS and precut papillotomy (OR 1.63; $95 \% \mathrm{Cl}$ 0.48-5.47). However, the rate of PEP was higher in TPS compared to precut fistulotomy (OR: 4.62; 95\% Cl: 1.36-15.72). The rate of bleeding and perforation did not differ between the four advanced techniques. From this study, precut fistulotomy appears to have better outcomes among these four most commonly used advanced techniques; however, it is important to keep in mind that the choice of which technique to pursue can vary depending on a multitude of factors, including experience of the endoscopist, equipment availability, and variations in patient anatomy.

While many studies initially suggested that performing a precut may increase the risk of PEP, this increased risk has not been seen when the precut is done earlier in the procedure (also known as early precut). In many cases, and depending on the clinical scenario, the risk of PEP after early precut may be even lower than when no precut is used. ${ }^{1,46-49} A$ recent metaanalysis of six randomised controlled trials, which included 898 patients, found that early precut not only increased the rate of biliary cannulation (RR: 1.87; 95\% Cl: 1.15-3.04), but also significantly reduced the risk of PEP compared to standard cannulation (RR: 0.49; 95\% Cl: 0.30-0.80). ${ }^{46}$ Thus, it is now thought that a higher risk of PEP after precut is only the consequence of increased papillary manipulation in cases of difficult biliary cannulation, and not the precut itself.50 


\section{RENDEZVOUS TECHNIQUES}

In rare cases where a precut technique fails or is not possible due to anatomical variations of the papilla, a rendezvous technique can be performed. These methods involve the anterograde passage of a wire through the papilla and into the duodenum, with subsequent selective biliary cannulation over the wire or in parallel to the wire. Due to the complex nature of these procedures, they should only be performed by experienced endoscopists and are generally only performed at specialised endoscopy centres. In the following section, the authors provide a brief overview of two rendezvous techniques.

\section{Percutaneous Transhepatic- Endoscopic Rendezvous}

The percutaneous-transhepatic-endoscopic rendezvous (PTE-RV) technique is a rendezvous technique that can be used in cases where initial biliary cannulation has failed, particularly in the setting of altered surgical anatomy, failure of selective insertion into the right intrahepatic duct, or a tight hilar biliary stricture where only a guidewire can be passed..$^{51}$ In this technique, percutaneous access to the bile duct is first achieved by an interventional radiologist. A guidewire is then threaded anterograde through the needle into the bile duct and advanced through the papilla, where the wire can then be used to facilitate conventional biliary cannulation. A retrospective study found PTE-RV to have a success rate of 92.9\%; however, the need for percutaneous access is a significant drawback to this technique. ${ }^{51}$

\section{Endoscopic Ultrasound-Guided Rendezvous}

In the endoscopic ultrasound-guided rendezvous (EUS-RV) technique, the bile duct (or pancreatic duct) is punctured via a transgastric or transduodenal approach, and a wire is subsequently passed anterograde through the papilla.52 A sphincterotome can then be directed over the guidewire or in parallel to the wire for biliary cannulation. Through this technique, a failed standard cannulation attempt can be salvaged during the same session without the need for a precut sphincterotomy. ${ }^{53}$ Furthermore, if biliary cannulation is still not possible via
EUS-RV, another recently described salvage technique, EUS-hybrid rendezvous technique, can be attempted. In this instance, a dilator is advanced into the biliary system for better guidewire manipulation. ${ }^{54}$ In a retrospective study comparing EUS-RV and precut papillotomy techniques, EUS-RV was associated with a higher rate of technical success (98.3\% versus $90.3 \%$, respectively; $p=0.03$ ), with no difference in complication rate. However, it remains unclear whether this procedure is costeffective and at what point technical competence is reached. ${ }^{55}$

\section{MANAGEMENT OF PERIDIVERTICULAR OR INTRADIVERTICULAR PAPILLAE}

Papillae located near or within a diverticulum are often difficult to visualise and access..$^{56}$ Over the years, various techniques for the management of peridiverticular or intradiverticular papillae have been described. The use of an endoscopic clip or forceps to retract an overlying diverticular rim has been reported to be a helpful technique to expose and properly orient the ampulla. ${ }^{57-61}$ One study found the attachment of a clear cap to the end of a forward-viewing endoscope helpful in revealing papillae that were difficult to find. ${ }^{62}$ Submucosal saline injection has also been described as a method of everting the papillary opening to assist cannulation of the papillary orifice. ${ }^{63}$ At times, advancement of the duodenoscope head into the diverticula is needed for cannulation of intradiverticular papillae; however, blind probing of the diverticulum is dangerous and should generally be avoided. Some cases require the use of rendezvous procedures, as described above. ${ }^{64,65}$

\section{SYNOPSIS OF BEST PRACTICES APPROACH}

While cannulation techniques vary based on variables such as region of the world, institution, individual physician preference, and papilla- and other patient-specific factors, the following is a recommended approach to selective biliary cannulation based on the authors' experience and the available published data (Figure 2). 


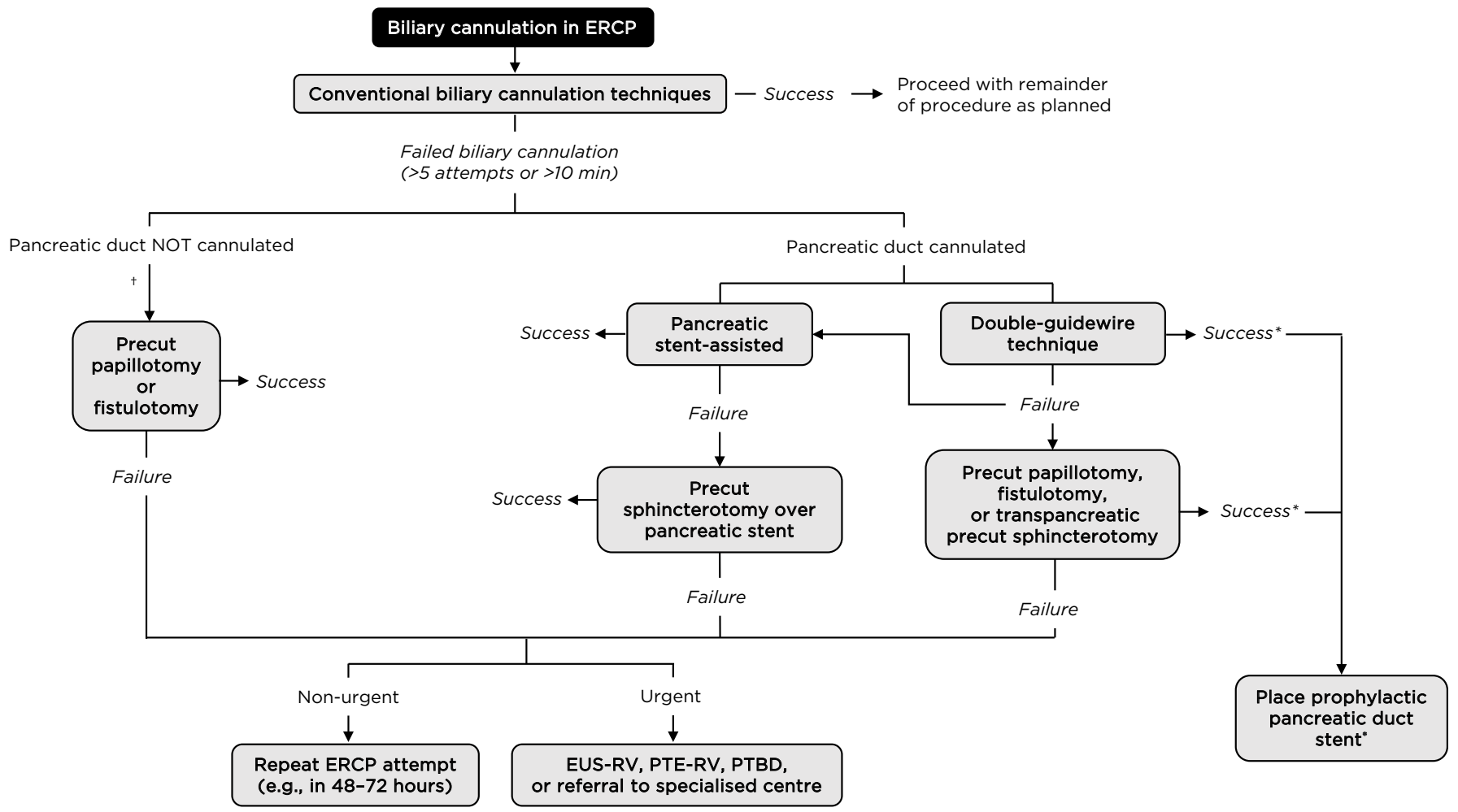

Figure 2: A proposed management algorithm for difficult biliary cannulation.

*Patients who have the pancreatic duct cannulated (intentional or inadvertent) should generally have a pancreatic duct stent placed to reduce the risk of post-ERCP pancreatitis, unless an alternative prophylactic measure is deemed to be equally or more clinically appropriate.

†If false tract created, intramural incision can be attempted.

ERCP: endoscopic retrograde cholangiopancreatography; EUS-RV: endoscopic ultrasound-guided rendezvous; PTERV: percutaneous transhepatic-endoscopic rendezvous; PTBD: percutaneous transhepatic biliary drainage.

The authors first visualise the major papilla and assess its size, associated features, and peripapillary anatomy. While the authors generally attempt conventional biliary cannulation techniques in the majority of cases with non-surgically altered anatomy, cases with particularly challenging anatomy may benefit from early adoption of advanced cannulation techniques.

As shown in Figure 2, when starting with conventional cannulation techniques and encountering difficulty with selective biliary cannulation, the authors typically select an advanced technique based on whether or not the pancreatic duct was cannulated. Regardless of the technique chosen, if the pancreatic duct is cannulated, the authors generally recommend the placement of a pancreatic duct stent or an alternative prophylactic measure prior to the end of the procedure to reduce the risk of PEP. Rendezvous techniques are only attempted if other more straightforward techniques fail.

\section{AREAS OF NEED AND FUTURE DIRECTIONS}

Over the past several decades, novel techniques and tools have been developed to address difficult biliary cannulation. In addition to continued refinements in these techniques, the authors see several areas that could benefit from further study. Firstly, although risk factors for difficult biliary cannulation have been identified, there are currently no well-established risk assessment tools that can predict, a priori, difficult biliary cannulation. The ability to predict which patients 
will need advanced techniques could be useful, as this could impact management plans, including the consent process (patients with a higher score may be at higher risk of adverse events and could be counselled or consented accordingly) and scheduling of procedures (patients that potentially require advanced techniques may need to be scheduled for a longer time in the endoscopy suite). An ideal tool would be based on readily available variables, easy to calculate, provide a risk estimate that is easy to understand (e.g., percentage or percentage range), and be accurate. Secondly, it would be useful to have a scoring system, ostensibly based on machine learning models, that can reliably predict the likelihood of adverse events related to difficulty biliary cannulation (e.g., PEP, perforation, or bleeding). Thirdly, patients with surgicallyaltered anatomy also remain a challenge, and it is unclear to date what the best management approach for biliary cannulation may be (of the various options that currently exist, including the relatively new addition of EUS-directed transgastric ERCP). Lastly, more data are needed to determine which patients (and providers) are best suited for early (or even first-line) implementation of precut sphincterotomy or suprapapillary fistulotomy.

\section{CONCLUSION}

ERCP has become an indispensable tool in the diagnosis and management of many pancreaticobiliary diseases. However, it remains a challenging procedure despite technological advances. When selective biliary cannulation is unsuccessful with standard techniques, a variety of advanced cannulation techniques can be attempted, including the use of pancreatic ductassisted (e.g., double-guidewire and pancreatic stent), precut, and rendezvous techniques. One may also consider calling for back-up (if a more experienced endoscopist is nearby) or stopping the procedure, especially if there appears to be a complication or if the patient is not tolerating the procedure well. Unsuccessful cases can be re-attempted at a later time or referred to a more specialised centre. There are currently many advanced techniques for biliary cannulation; the decision of which technique to pursue should ultimately take into consideration the endoscopist's experience, available equipment and staff, the disease being treated, and anatomical as well as other patientlevel considerations.

\section{References}

1. Cennamo $\mathrm{V}$ et al. Can early precut implementation reduce endoscopic retrograde cholangiopancreatography-related complication risk? Meta-analysis of randomized controlled trials. Endoscopy. 2010;42(5):381-8.

2. Andriulli $A$ et al. Incidence rates of post-ERCP complications: a systematic survey of prospective studies. Am J Gastroenterol. 2007;102(8):1781-8.

3. Harewood GC. An assessment of the learning curve for precut biliary sphincterotomy. Am J Gastroenterol. 2002;97(7):1708-12

4. Dumonceau JM et al. A new method of achieving deep cannulation of the common bile duct during endoscopic retrograde cholangiopancreatography. Endoscopy. 1998;30(7):S80.

5. Mammen A, Haber G. Difficult biliary access. Gastrointest Endosc Clin N Am. 2015;25(4):619-30.

6. Grönroos JM et al. Double-guidewireassisted biliary cannulation: experiences from a single tertiary referral center. Surg Endosc. 2011;25(5):1599-602

7. Maeda S et al. Prospective randomized pilot trial of selective biliary cannulation using pancreatic guide-wire placement. Endoscopy. 2003;35(9):721-4.

8. Tse F et al. Double-guidewire technique in difficult biliary cannulation for the prevention of post-ERCP pancreatitis: a systematic review and meta-analysis. Endoscopy. 2017:49(1):15-26.

9. Goldberg E et al. Pancreatic-duct stent placement facilitates difficult common bile duct cannulation. Gastrointest Endosc. 2005;62(4):592-

10. Sofuni A et al. Prophylaxis of post-endoscopic retrograde cholangiopancreatography pancreatitis by an endoscopic pancreatic spontaneous dislodgement stent. Clin Gastroenterol Hepatol. 2007;5(11):1339-46.
11. Singh $\mathrm{P}$ et al. Does prophylactic pancreatic stent placement reduce the risk of post-ERCP acute pancreatitis? A meta-analysis of controlled trials. Gastrointest Endosc. 2004;60(4):544-50.

12. Ito $\mathrm{K}$ et al. Can pancreatic duct stenting prevent post-ERCP pancreatitis in patients who undergo pancreatic duct guidewire placement for achieving selective biliary cannulation? A prospective randomized controlled trial. J Gastroenterol. 2010;45(11):1183-91.

13. Phillip $\vee$ et al. Pancreatic stenting to prevent post-ERCP pancreatitis: a randomized multicenter trial. Endosc Int Open. 2019;7(7):E860-8.

14. Choudhary A et al. Pancreatic stents for prophylaxis against post-ERCP pancreatitis: a meta-analysis and systematic review. Gastrointest Endosc. 2011;73(2):275-82.

15. Akbar A et al. Rectal nonsteroidal anti-inflammatory drugs are superior to pancreatic duct stents in preventing pancreatitis 
after endoscopic retrograde cholangiopancreatography: a network meta-analysis. Clin Gastroenterol Hepatol. 2013;11(7):778-83.

16. Mazaki T et al. Prophylactic pancreatic stent placement and post-ERCP pancreatitis: an updated meta-analysis. J Gastroenterol. 2014;49(2):343-55.

17. Shi $Q Q$ et al. Placement of prophylactic pancreatic stents to prevent post-endoscopic retrograde cholangiopancreatography pancreatitis in high-risk patients: a meta-analysis. World J Gastroenterol. 2014:20(22):7040-8.

18. Fan JH et al. Updated meta-analysis of pancreatic stent placement in preventing post-endoscopic retrograde cholangiopancreatography pancreatitis. World J Gastroenterol. 2015;21(24):7577-83.

19. Vadalà di Prampero SF et al. Endoscopic and pharmacological treatment for prophylaxis against postendoscopic retrograde cholangiopancreatography pancreatitis: a meta-analysis and systematic review. Eur J Gastroenterol Hepatol. 2016;28(12):1415-24.

20. Sugimoto $M$ et al. Pancreatic stents to prevent post-endoscopic retrograde cholangiopancreatography pancreatitis: a meta-analysis. World J Metaanal. 2019;7(5):249-58.

21. Dumonceau JM et al. Prophylaxis of post-ERCP pancreatitis: European Society of Gastrointestinal Endoscopy (ESGE) Guideline updated June 2014. Endoscopy. 2014;46(09):799-815.

22. Das A et al. Pancreatic-stent placement for prevention of post-ERCP pancreatitis: a costeffectiveness analysis. Gastrointest Endosc. 2007;65(7):960-8.

23. Dumonceau J-M et al. ERCP-related adverse events: European Society of Gastrointestinal Endoscopy (ESGE) Guideline. Endoscopy. 2020;52(2):12749.

24. Fogel EL et al. Increased selective biliary cannulation rates in the setting of periampullary diverticula: main pancreatic duct stent placement followed by pre-cut biliary sphincterotomy. Gastrointest Endosc. 1998;47(5):396-400

25. Kubota K et al. Needle-knife precut papillotomy with a small incision over a pancreatic stent improves the success rate and reduces the complication rate in difficult biliary cannulations. J Hepatobiliary Pancreat Sci. 2013;20(3):382-8.

26. Katsinelos $P$ et al. Comparison of three types of precut technique to achieve common bile duct cannulation: a retrospective analysis of 274 cases. Dig Dis Sci. 2012:57(12):3286-92

27. Freeman ML et al. Complications of endoscopic biliary sphincterotomy. N Engl J Med. 1996;335(13):909-18.

28. Classen M, Demling L. [Endoscopic sphincterotomy of the papilla of vater and extraction of stones from the choledochal duct (author's transl)]. 1974;99(11):496-7. (In German)

29. Binmoeller KF et al. Papillary roof incision using the Erlangen-type precut papillotome to achieve selective bile duct cannulation. Gastrointest Endosc. 1996;44(6):689-95.

30. Palm J et al. Safety of Erlangen precut papillotomy: an analysis of 1044 consecutive ERCP examinations in a single institution. J Clin Gastroenterol. 2007;41(5):528-33.

31. de Weerth A et al. Primary precutting versus conventional over-the-wire sphincterotomy for bile duct access: a prospective randomized study. Endoscopy. 2006;38(12):1235-40.

32. Kawakami $\mathrm{H}$ et al. Transpapillary selective bile duct cannulation technique: review of Japanese randomized controlled trials since 2010 and an overview of clinical results in precut sphincterotomy since 2004. Dig Endosc. 2016;28(Suppl 1):77-95.

33. Kapetanos D et al. Case series of transpancreatic septotomy as precutting technique for difficult bile duct cannulation. Endoscopy. 2007;39(9):802-6.

34. Chan $\mathrm{CH}$ et al. Wire assisted transpancreatic septotomy, needle knife precut or both for difficult biliary access. J Gastroenterol Hepatol. 2012;27(8):1293-7.

35. Zang J et al. Guidewire-assisted transpancreatic sphincterotomy for difficult biliary cannulation: a prospective randomized controlled trial. Surg Laparosc Endosc Percutan Tech. 2014;24(5):429-33.

36. Pécsi D et al. Transpancreatic sphincterotomy has a higher cannulation success rate than needleknife precut papillotomy - a metaanalysis. Endoscopy. 2017;49(9):87487.

37. Sakai $Y$ et al. Transpancreatic precut papillotomy in patients with difficulty in selective biliary cannulation. Hepatogastroenterology. 2011;58(112):1853-8.

38. Artifon ELA et al. A new approach to the bile duct via needle puncture of the papillary roof. Endoscopy. 2005:37(11):1158.

39. Artifon ELA et al. Suprapapillary needle puncture for common bile duct access: laboratory profile. Arq Gastroenterol. 2006;43(4):299-304.

40. Artifon ELA et al. Management of common bile duct stones in cirrhotic patients with coagulopathy: a comparison of suprapapillary puncture and standard cannulation technique. Dig Dis Sci.
2011;56(6):1904-11.

41. Mavrogiannis $C$ et al. Needle-knife fistulotomy versus needle-knife precut papillotomy for the treatment of common bile duct stones. Gastrointest Endosc. 1999;50(3):3349.

42. Burdick JS et al. Intramural incision technique. Gastrointest Endosc. 2002;55(3):425-7.

43. Goenka MK, Rai VK. Burdick's technique for biliary access revisited. Clin Endosc. 2015;48(1):20-3.

44. Misra SP, Dwivedi M. Intramura incision technique: a useful and safe procedure for obtaining ductal access during ERCP. Gastrointest Endosc. 2008;67(4):629-33.

45. Pécsi $\mathrm{D}$ et al. Transpancreatic sphincterotomy is effective and safe in expert hands on the short term. Dig Dis Sci. 2019;64(9):2429-44.

46. Chen $\mathrm{J}$ et al. Assessing quality of precut sphincterotomy in patients with difficult biliary access: an updated meta-analysis of randomized controlled trials. J Clin Gastroenterol. 2018;52(7):573-8.

47. Sundaralingam $P$ et al. Early precut sphincterotomy does not increase risk during endoscopic retrograde cholangiopancreatography in patients with difficult biliary access: a metaanalysis of randomized controlled trials. Clin Gastroenterol Hepatol. 2015;13(10):1722-9.e2.

48. Choudhary A et al. Effect of precut sphincterotomy on post-endoscopic retrograde cholangiopancreatography pancreatitis: a systematic review and meta-analysis. World J Gastroenterol. 2014;20(14):4093-101.

49. Gong B et al. Does precut technique improve selective bile duct cannulation or increase post-ERCP pancreatitis rate? A meta-analysis of randomized controlled trials. Surg Endosc. 2010;24(11):2670-2680.

50. Manes $G$ et al. An analysis of the factors associated with the development of complications in patients undergoing precut sphincterotomy: a prospective, controlled, randomized, multicenter study. Am J Gastroenterol. 2009;104(10):2412-2417.

51. Yang MJ et al. Usefulness of combined percutaneous-endoscopic rendezvous techniques after failed therapeutic endoscopic retrograde cholangiography in the era of endoscopic ultrasound guided rendezvous. Medicine (Baltimore). 2017;96(48):e8991.

52. Shiomi $\mathrm{H}$ et al. Endoscopic ultrasound-guided rendezvous technique for failed biliary cannulation in benign and resectable malignant biliary disorders. Dig Dis Sci. 2018:63(3):787-96.

53. Iwashita T et al. Endoscopic 
ultrasound-guided rendezvous for biliary access after failed cannulation. Endoscopy. 2012;44(1):60-5.

54. Iwashita T et al. EUS-guided hybrid rendezvous technique as salvage for standard rendezvous with intrahepatic bile duct approach. PloS One. 2018;13(8):e0202445.

55. Yoon WJ, Brugge WR. EUS-guided biliary rendezvous: EUS to the rescue. Gastrointest Endosc. 2012;75(2):3601.

56. Lobo DN et al. Periampullary diverticula: consequences of failed ERCP. Ann R Coll Surg Engl. 1998;80(5):326-31.

57. Cappell MS et al. Endoclips to facilitate cannulation and sphincterotomy during ERCP in a patient with an ampulla within a large duodenal diverticulum: case report and literature review. Dig Dis Sci. 2015;60(1):168-73.

58. Huang $\mathrm{CH}$ et al. Endoscopic retrograde cholangiopancreatography (ERCP) for intradiverticular papilla: endoclip-assisted biliary cannulation. Endoscopy. 2010;42(S 2):E223-4.

59. Balkrishanan $M$ et al. Cannulation in patients with large periampullary diverticulum using SpyBite miniforceps. Clin Exp Hepatol. 2018:4(1):41-2.

60. Inamdar S et al. Difficult biliary cannulation achieved in the setting of periampullary diverticulum with the simultaneous use of biopsy forceps and wire-guided cannulation. VideoGIE. 2017;2(2):25-6.

61. Kim KH, Kim TN. A new technique for difficult biliary cannulation using endobiliary forceps in a patient with a periampullary diverticulum. Endoscopy. 2017;49(8):824-6.

62. Myung DS et al. Cap-assisted ERCP in patients with difficult cannulation due to periampullary diverticulum. Endoscopy. 2014;46(4):352-5.

63. Lee $\mathrm{K}$ et al. Papillary cannulation facilitated by submucosal saline injection into an intradiverticular papilla. Clin Endosc. 2019;52(1):83-6.

64. Calvo MM et al. The rendezvous technique for the treatment of choledocholithiasis. Gastrointest Endosc. 2001:54(4):511-3.

65. Dhir $\vee$ et al. EUS-guided biliary rendezvous using a short hydrophilic guidewire. J Interv Gastroenterol. 2011;1(4):153-9. 